\title{
Use of hormonal emergency contraception at a university health centre over a 6 year period
}

\author{
JF Hugh Porter, MB ChB, MSc, MRCGP, DFFP, DRCOG, Principal in General Practice \\ Correspondence: Dr JF Hugh Porter, Principal in General Practice, Nottingham University Health Service, Cripps Health \\ Centre, University Park, Nottingham, NG7 2QW, UK. Tel: 0115950 1654, Fax: 01159480347.
}

(Accepted August $31^{\text {st }}, 2000$ )

\begin{abstract}
Summary
This was a retrospective review of the use of emergency hormonal contraception at a university-based health centre over a 6 year period. Usage was greater than noted in previous studies. Condom problems, or not using any form of contraception, were the main reasons for requests. Users were significantly more likely to be smokers than the base population.
\end{abstract}

\section{Keywords}

emergency contraception, students, university

\section{Key message points \\ - On average $11.2 \%$ of females between the ages of $17-34$ who were registered with a university health centre used hormonal emergency contraception per year. \\ - Problems with condoms were the predominant reason for requests \\ - Users were significantly more likely to be current smokers. \\ - Pregnancy rates were below those expected from previous studies.}

\section{Introduction}

Since 1945 there has been a huge increase in the number of people undertaking higher education. This expansion started with the publication of the Robbins Committee Report in 1963, and has continued through to the present day. Current estimates now suggest that soon nearly one in three will enter some form of higher education. ${ }^{1}$ In light of this, it is somewhat surprising that there has been little specific research on student's use of contraceptive methods and services. This is especially true where hormonal emergency contraception (EC) is concerned, and what scarce evidence is available is mainly based on studies carried out abroad.

In the United States, the University of Rochester Health Service looked at 6 years use of EC between 1985 and $1991 .^{2}$ It was given 209 times, with a pregnancy rate of $1.9 \%$, but little in the way of other information was collected in terms of why it was needed. More recently students requesting $\mathrm{EC}$ from the health centre serving a Dublin university were studied over a 3.5 year period. ${ }^{3}$ It was provided on 434 occasions. This study was focused on the effect of educational input on contraceptive use, but did record the reason for requests. Forty-two percent had condom problems, whilst nearly $50 \%$ had failed to use any form of contraception.

\section{Method}

The University of Nottingham has a purpose built health centre based on campus, where the majority of students and some staff are registered. Since early 1993 all requests for EC have been recorded on a specifically designed computer template. This collects details of the reason for the request, as well as other information such as cervical smear status, smoking status, and future contraceptive choices. The practice until recently did all its own on call, and therefore requests for $\mathrm{EC}$ at weekends and out of hours are also captured in the data.

A computer search was undertaken to review all the information collected over a 6 year period from 1st January 1994 to 31 st December 1999. Details of unwanted pregnancies are recorded on the computer at presentation or, if occurring elsewhere, are noted when any documentation arrives at the practice. Details of the practice population over the same period were also reviewed.

\section{Results}

EC was prescribed on 4093 occasions to 3721 patients over the 6 year period, Table 1 showing the breakdown by year. This is set against an average practice list size of female patients over the same period of 6252 , of whom $5520(88 \%)$ were in the 17-34 year age group.

Table 1 Number of patients and number of prescriptions given for hormonal emergency contraception per year

\begin{tabular}{lcc}
\hline Year & Number of patients & Number of prescriptions \\
\hline 1994 & 434 & 469 \\
1995 & 530 & 576 \\
1996 & 698 & 782 \\
1997 & 670 & 758 \\
1998 & 677 & 771 \\
1999 & 712 & 737 \\
Total & 3721 & 4093 \\
\hline
\end{tabular}

The reason EC was requested is illustrated in Table 2. The percentage of patients who took EC and were also current smokers was $24.8 \%$, against the overall practice rate for females in the $15-54$ year age band of $11.1 \%$ (odds ratio 2.98 [95\% confidence interval 2.74 to 3.23$]$ ). Blood pressure was measured in $3246(87.2 \%)$ of patients. Future contraceptive choices are illustrated in Table 3 .

Table 2 Reasons why hormonal emergency contraception was requested

\begin{tabular}{lrr}
\hline Reason for request & Number of requests \\
\hline Condom split / burst & 2028 & $(55.13 \%)$ \\
Condom came off & 566 & $(15.39 \%)$ \\
No contraception used & 712 & $(19.36 \%)$ \\
Forgotten pills & 248 & $(6.75 \%)$ \\
Gastro-enteritis with OCP & 33 & $(0.89 \%)$ \\
Antibiotics with OCP & 62 & $(1.68 \%)$ \\
Other & 30 & $(0.81 \%)$ \\
Total & 3679 & $(100.00 \%)$ \\
\hline
\end{tabular}

Finally, the number of unwanted pregnancies following use of EC was reviewed. In all there were 36 unwanted pregnancies following use of EC in this period. 
Table 3 Future contraceptive choices of users of hormonal emergency contraception

\begin{tabular}{lrr}
\hline Future method chosen & \multicolumn{2}{c}{ Number of patients } \\
\hline Condom & 1675 & $(51.8 \%)$ \\
OCP & 1428 & $(44.2 \%)$ \\
POP & 27 & $(0.8 \%)$ \\
Diaphragm & 20 & $(0.6 \%)$ \\
Other & 19 & $(0.6 \%)$ \\
Depo Provera & 14 & $(0.4 \%)$ \\
IUCD & 11 & $(0.4 \%)$ \\
Not required & 39 & $(1.2 \%)$ \\
Total & 3233 & $(100 \%)$ \\
\hline
\end{tabular}

\section{Discussion}

These results show significant use of hormonal EC by the practice population, with on average $11.2 \%$ of females between the ages of 17-34 years using hormonal EC per year. This figure is, in fact, likely to be an under-estimation as visits to family planning services and student's 'home doctors' during vacations are not recorded. The practice has tried to make EC as accessible as possible over the last 6 years and this may explain the seemingly high frequency of use. The characteristics of the practice population obviously play a part as well, with many sexually active young women, who by nature of their situation (embarking on higher education with a view to subsequent careers) have a strong incentive to avoid any chance of an unplanned pregnancy. Unfortunately there are few data available about the rate of use of EC by any comparable population, though broader population studies and prescription data suggest lower rates of use. ${ }^{4-6}$

In terms of reason for request it is, perhaps, not surprising that condom problems make up the majority of requests, both because this method of contraception is popular amongst students, ${ }^{3}$ but also because it is probably seen as a valid reason for request when in fact no contraception had been used. Work on condom breakage $e^{7,8}$ suggests that the high rates reported are unlikely, and may be accounted for by this social desirability effect. The rate of condom problems reported here is, however, similar to that noted in other studies. ${ }^{3,9}$ The fact that nearly $20 \%$ of students admitted to using no form of contraception is of concern given the population base, whilst other problems, most notably those concerning the combined contraceptive pill, make up a seemingly small number of requests.

It is interesting to note that users of hormonal EC were far more likely to be smokers than the base population, and this finding is in keeping with previous work. ${ }^{4}$ One possible hypothesis to explain this is that those individuals who are happy to accept the risks of smoking are also more likely to accept risks in general, one facet of this being the risk of unprotected sexual intercourse.

Future contraceptive choices show an exceptionally narrow spectrum of preference towards condoms or the combined contraceptive pill. Other methods hardly register with the population in the study and unpublished practice data confirm the skew towards condoms and the combined oral contraceptive pill as the contraceptives of choice in this group.

Pregnancy rates following use of hormonal EC are well documented, ${ }^{10}$ but the rate here is far below that expected. It is possible that some of the discrepancy is due to poor data capture, students returning home to have terminations of pregnancy, but this number would have to be considerable to make up the difference. More plausibly it may be that the students involved have a very low threshold for seeking EC, especially as it is easily accessible.

\section{Conclusion}

Use of EC in the practice population of a student health service was higher than reported elsewhere, but there were relatively few pregnancies subsequent to its use. Making sure access to EC is easy for such populations is therefore likely to be very important. Users are far more likely to smoke than comparable patients, and further research into the value of this correlation may be valuable when considering the proactive education/targeting of at-risk students.

\section{Acknowledgements}

The author would like to thank his partners, Drs White, Hollins, Nash, Gibbs and Armitage for their help in recording the data over the 6 year period.

\section{Statements on funding and competing interests}

Funding. None.

Competing interests. None.

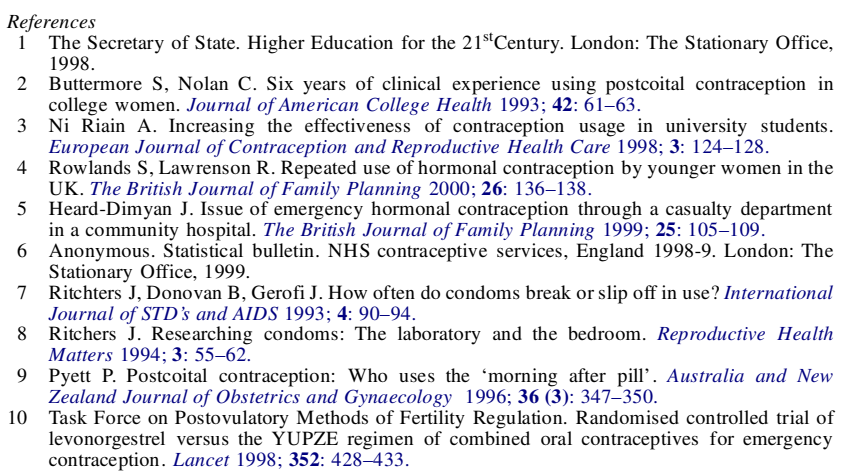

Buttermore S, Nolan C. Six years of clinical experience using postcoital contraception in (1993; 42: 61-63. by younger women in the K. The British Journal of Family Planning 2000; 26: 136-138.

. Anonymus. Staspital. The British Journal of Family Planning 1999, 25: 105-109.

Zealand Journal of Obstetips 1 Gy contraception. Lancet 1998: 352: 428-433. 